\title{
Efficacy of short term versus long term antibiotic therapy in preventing deep wound infections in elective orthopaedic surgeries
}

\author{
Saurabh Chandrakar ${ }^{1}$, Ankit Mittal ${ }^{2 *}$, Jalaz Jain ${ }^{3}$, Himanshu Bansal ${ }^{1}$, Prateek Ahlawat ${ }^{4}$, \\ S. S. Sangwan ${ }^{1}$, Rakesh Sharma ${ }^{1}$, Hitanshi Arora ${ }^{5}$
}

\author{
${ }^{1}$ Department of Orthopaedics, ${ }^{2}$ Department of Sports Medicine, ${ }^{5}$ Department of Obstetrics and Gynaecology, Pt. BD \\ Sharma PGIMS, Rohtak, Haryana, India \\ ${ }^{3}$ Department of Orthopaedics, Satyawadi Raja Harishchandra Hospital, Narela, New Delhi, India \\ ${ }^{4}$ Cygnus Multispeciality Hospital, Kurukshetra, Haryana, India
}

Received: 25 August 2020

Revised: 19 September 2020

Accepted: 21 September 2020

\section{*Correspondence:}

Dr. Ankit Mittal,

E-mail: ankit.mittal2310@gmail.com

Copyright: ( ) the author(s), publisher and licensee Medip Academy. This is an open-access article distributed under the terms of the Creative Commons Attribution Non-Commercial License, which permits unrestricted non-commercial use, distribution, and reproduction in any medium, provided the original work is properly cited.

\begin{abstract}
Background: Comparison of the efficacy of short term (up to 48 hours) versus long term (five days) antibiotic therapy in preventing deep wound infections in elective orthopaedic surgeries.

Methods: Two hundred patients of all ages and both sexes were divided into two groups of 100 patients. One group received long term antibiotic treatment consisting of 2 days intra-venous cefoperazone sulbactam 1.5 gm twice daily and intra-venous amikacin $500 \mathrm{mg}$ twice daily followed by 3 days of oral amoxicillin clavulunate $625 \mathrm{mg}$ thrice daily. Other group received short term antibiotic of 2 days intra-venous cefoperazone sulbactam 1.5 gm twice daily and intra-venous amikacin $500 \mathrm{mg}$ twice daily. Comparison of SSI was done with age, sex, BMI, pre-operative haemoglobin, TLC, duration of surgery in both the groups.

Results: In group I and group II respectively, average duration of surgery in procedures involving implants was $65.02 \pm 27.41$ and $59.47 \pm 20.27$ minutes and non implant related procedures was $53.66 \pm 23.97$ and $53.74 \pm 22.40$ minutes. Overall incidence of SSI in Group I and Group II was 14\% and 10\% respectively. Mean infection in the present study was $12 \%$.

Conclusions: It was concluded that in clean orthopaedic elective surgeries short term antibiotics regimen is as effective as long term antibiotics regimen. Continuing antibiotics for more than two days is associated with drug related complications like allergic reactions and gastrointestinal upset, adverse interactions in other drugs, development of resistant organisms and it adds to overall cost of treatment.
\end{abstract}

Keywords: Surgical site infection, Antibiotic therapy, Wound infection, Orthopedic surgery

\section{INTRODUCTION}

It was rightly stated by Moynihan way back in 1920, that every operation in surgery is an experiment in bacteriology. ${ }^{1}$ Infection at or near surgical incisions within 30 days of an operative procedure, dubbed surgical site infection (SSI). The centre for disease control and prevention (CDC) considers SSI to include both incisional SSI and organ space SSI. Incisional SSI is subdivided in to superficial and deep SSI, depending on whether the infection is limited to the skin and subcutaneous tissue only (superficial SSI) or extends into the deeper tissues, such as the fascial and muscular layers of the body wall (deep SSI). Organ/space SSI is an infection that occurs anywhere within the operative field 
other than where the body wall tissues were incised. ${ }^{2}$ SSI accounts for $15 \%$ of all nosocomial infections and, among surgical patients, represents the most common nosocomial infection. ${ }^{3}$ Surgical wounds are stratified into four classes; class I (clean), class II (clean-contaminated), class III (contaminated) and class IV (dirty-infected).

Prophylactic antibiotics have been described as antibiotics given for the purpose of preventing infection when infection is not present but the risk of postoperative infection is present. ${ }^{4}$ The use of prophylactic antibiotic therapy before the induction of anesthesia and continuing it after surgery is an accepted method of avoiding postoperative infection. ${ }^{5-6}$ All infections cannot be prevented by the use of prophylactic antibiotics. Each patient has a unique set of immune defences and therefore different risks of infection. Use of broadspectrum antibiotics contributes to the development of multi-drug-resistant organisms. ${ }^{7}$ Similar to the rise in penicillin resistance there has been, in the past decade, a rise in the prevalence of methicillin resistant Staphylococcus aureus surgical site infections. ${ }^{8}$ The goal of antimicrobial prophylaxis is to achieve serum and tissue drug levels that exceed, for the duration of the operation, the minimum inhibitory concentration for the organisms likely to be encountered during the operation. The idea is not to sterilize tissues but to reduce the microbial burden of intra-operative contamination to a level that cannot overwhelm host defenses.

There is no consensus with regard to the optimal duration of prophylaxis. The standard practice is to administer prophylactic intravenous antibiotics only on the day of surgery in Western countries. ${ }^{9-12}$ Benefits of perioperative antimicrobial prophylaxis need to be balanced against risks. Patient risk factors thought to increase the chance of SSI include advanced age, poor nutritional status, obesity, smoking, diabetes, altered immune response, length of preoperative stay, colonization with micro-organisms, coexisting infections remote from operative site, setting of the procedure (elective or emergent, clean or contaminated, and others). ${ }^{13}$ Certain procedures are associated with low risk for a SSI, and the risks of antimicrobial prophylaxis may outweigh the benefits. Risks include allergic reactions, toxic side effects of antimicrobials, adverse interactions with other drugs, and development of resistant organisms.

The most important consideration in choosing an antibiotic for prophylaxis is its spectrum of action. While the chosen antibiotic may not cover the entire spectrum of organisms that may be encountered, it must be active against the bacteria that commonly cause postoperative infection. Other factors to consider include the pharmacokinetics and pharmacodynamics of the drug. The final consideration should be the cost associated with the use of the antibiotic, which should include the costs of drug monitoring, administration, repeat doses, adverse effects, and failure of prophylaxis (i.e., wound infection sequel). ${ }^{14-15}$

The purpose of conducting this study is to know whether prophylactic administration of antibiotics for short term can decrease postoperative morbidity, shorten hospitalization, reduce the overall cost attributable to infection and prevent un-necessary use of antibiotics for longer periods.

\section{METHODS}

In the present study, a total of 200 patients, admitted in the orthopaedic wards of Pt. BD Sharma, post graduate institute of medical sciences from November 2012 to April 2014, of all ages and both sexes were divided in to two groups of 100 patients each. Patients who were healthy and coming to the hospital for soft tissue procedures or procedures involving implants (such as plating, nailing, arthroplasties) were included.

The patients in the first group were given peri-operative prophylactic intravenous antibiotic intra-venous cefoperazone sulbactam $1.5 \mathrm{gm}$ and intra-venous amikacin $500 \mathrm{mg} 30$ minutes prior to the induction of anesthesia, which was continued in the post operative period for $48 \mathrm{hrs}$ as twice daily doses after which it was discontinued. In the patients of the second group the same protocol was followed as in the first group, and after first $48 \mathrm{hrs}$ of post-operative period, they were further given an oral amoxicillin clavulunate $625 \mathrm{mg}$ thrice daily as a part of post surgical prophylaxis for 3 more days.

In each group, equal number patients with procedures involving implants and soft tissue procedures were included. Any discharge/pus if present was collected and sent for culture and sensitivity. The organism was identified and its antimicrobial susceptibility carried out following standard protocols. Patient was admitted prior to surgery, operative area cleaned of hairs night prior to surgery (use of razors over operative area avoided). Routine blood investigations were carried out in all the patients. All necessary precautions were followed such as using autoclaved gloves, sterile instruments and drapes, standard surgical scrub for 5 minutes before operation, cleaning of operative area with povidone iodine and spirit, minimal tissue handling, maintaining of adequate hemostasis and minimal use of cautery, using drains wherever necessary.

Criteria for judging whether or not a wound infection occurred were according to Pavel et al. ${ }^{16}$ If a wound drained purulent material irrespective of whether an organism was cultured or not it was considered infected. When a wound became red, painful or tender, swollen and hot for more than 48 hours, the wound was considered infected. When the patient had fever for more than 48 hours and no other cause could be traced, the wound was considered infected. If the patient had a stitch 
abscess with a small amount of purulence directly around a suture, but without any signs of inflammation or fever, the wound was not considered infected.

Patient's were followed with daily temperature chart, with changing of wound dressing on second postoperative day and signs of wound infection like local erythema, induration, local rise of temperature and any discharge were looked for. Sutures were removed twelve days after surgery. If an infection is noted, sutures were removed earlier, discharge was sent for culture and sensitivity testing was done.

Patients were followed up for at least 12 weeks and complications noted. Deep infection was considered as an infection that occurred at least 3 weeks after the primary operation and necessitated surgical debridement.

\section{Statistical analysis}

Data from both groups was collected and analyzed with help of IBM SPSS software (version 20.0), a p value of less than 0.05 considered as statistically significant. Chi square test and fisher exact test was used for qualitative data and unpaired student's t-test was used for quantitative data.

\section{RESULTS}

Out of the 200 patients enrolled in the study, 100 patients in each group were analysed after randomisation, they were further divided in equal groups of implant and nonimplant surgeries. The baseline demographic characteristics including baseline investigations and duration of the study were comparable in both the groups (Table 1).

Table 1: Baseline demographic parameters.

\begin{tabular}{|lllllll|}
\hline & Implant group & & \multicolumn{3}{c|}{ Non- implant group } \\
& Group I & Group II & P value & Group I & Group II & P value \\
\hline Age & $39.66 \pm 10.58$ & $40.14 \pm 23.03$ & $>0.05$ & $30.24 \pm 19.35$ & $26.9 \pm 18.93$ & $>0.05$ \\
\hline Sex (M/F) (\%) & $70 / 30$ & $72 / 28$ & 0.825 & $64 / 36$ & $68 / 32$ & 0.672 \\
\hline $\begin{array}{l}\text { Smoker/non smoker } \\
(\%)\end{array}$ & $32 / 68$ & $42 / 58$ & 0.300 & $78 / 22$ & $78 / 22$ & 1 \\
\hline $\begin{array}{l}\text { BMI } \\
\left(\mathbf{k g} / \mathbf{m}^{2}\right)\end{array}$ & $23.58 \pm 1.80$ & $22.95 \pm 1.97$ & $>0.05$ & $22.90 \pm 1.47$ & $23.08 \pm 2.07$ & $>0.05$ \\
\hline $\begin{array}{l}\text { HB } \\
(\text { g/dl) }\end{array}$ & $11.43 \pm 2.71$ & $\begin{array}{l}11.35 \pm 1.83 \\
\text { g/dl }\end{array}$ & $>0.05$ & $11.46 \pm 1.71$ & $11.37 \pm 1.67$ & $>0.05$ \\
\hline TLC & $8454 \pm 2323.10$ & $\begin{array}{l}8012 \pm 2093.68 \\
\text { x } 109 / 1\end{array}$ & $>0.05$ & $8638 \pm 2446.64$ & $8758 \pm 2562.29$ & $>0.05$ \\
\hline Duration of surgery & $65.02 \pm 27.41$ & $59.47 \pm 20.27$ & $>0.05$ & $53.66 \pm 23.97$ & $53.74 \pm 22.40$ & $>0.05$ \\
\hline
\end{tabular}

Table 2: Overall incidence of SSI in both groups.

\begin{tabular}{|llll|}
\hline $\begin{array}{l}\text { Infection } \\
(\mathbf{n = 1 0 0 )}\end{array}$ & $\begin{array}{l}\text { Group I } \\
\text { (long } \\
\text { duration) }\end{array}$ & $\begin{array}{l}\text { Group II } \\
\text { (short } \\
\text { duration) }\end{array}$ & P value \\
\hline $\begin{array}{l}\text { SSI infection } \\
\text { N (\%) }\end{array}$ & $14(14)$ & $10(10)$ & 0.384 \\
\hline $\begin{array}{l}\text { Impant group } \\
(\%)(\mathbf{\% = 5 0 )}\end{array}$ & 18 & 8 & 0.132 \\
\hline $\begin{array}{l}\text { Non-implant } \\
\text { group (\%) } \\
(\mathbf{n = 5 0 )}\end{array}$ & 12 & 10 & 0.749 \\
\hline
\end{tabular}

We observed that in the implant group, 9 patients $(18 \%)$ developed SSI in group I and 4 patients $(8 \%)$ developed in group II $(\mathrm{p}>0.05)$; similarly 6 patients $(12 \%)$ and 5 patients $(10 \%)$ developed SSI infection in group I and group II $(\mathrm{p}>0.05)$ respectively in the non-implant group. The overall incidence $(n=100 / 100)$ was comparable with $14 \%$ and $10 \%$ incidence of SSI in group I and II respectively (Table 2).
SSI infection cases with respect to their age groups in both groups without implants was observed in 4 cases in group I and 1 case in group II in the age group of 30-50 years having infection followed by 2 cases in group I and 3 cases in group II in $<30$ years age group $(p>0.05)$. Comparison of SSI infection cases with respect to their age groups in both groups with implants showed 2 cases each in age group of <30 years; 30-50 years and $>70$ years in group I and 1 case each in $<30$ and $>70$ years age group with SSI infection ( $\mathrm{p}>0.05)$.

SSI infection cases with respect to their sex groups in both groups without implants showed equal number of male i.e. 2 cases each and 4 female in group I and 3 female in group II suffered with infection ( $p>0.05)$. SSI infection cases with respect to their sex groups in both groups with implants showed male suffering most as compared to female. In our study, 7 male in group I and 3 male in group II suffered with infection as compared to 2 female in group I and 1 female in group II ( $p>0.05)$.

SSI infection cases with respect to their BMI showed 4 cases in group I and 4 cases in group II infected with SSI 
with BMI ranged from 20-25 ( $p>0.05$ ) with implants and without implants we noted that 6 cases in group I and cases in group II infected with SSI with BMI ranged from 20-25 ( $>0.05)$.

Comparison of SSI infection cases with respect to their $\mathrm{Hb}$ status in both groups without implants showed 4 cases in group I and 2 cases in group II infected with SSI with $8-10 \mathrm{~g} / \mathrm{dl} \mathrm{Hb}(\mathrm{p}>0.05)$ and with implants we noted that 1 case in group I and 1 case in group II infected with SSI in $<8 \mathrm{~g} / \mathrm{dl} \mathrm{Hb}$ followed by 4 in group I and 2 in group II with a range of $8-10 \mathrm{~g} / \mathrm{dl} \mathrm{Hb}(\mathrm{p}>0.05)$.

SSI infection cases with respect to their TLC level obtained in both groups without implants showed 2 cases each in group I and group II infected with SSI in $<8000$ and $8000-11000 \times 10^{9} / \mathrm{L}$ TLC $(\mathrm{p}>0.05)$ and with implants, we noted 5 cases in group I and 2 cases in group II infected with SSI in $<8000 \times 10^{9} / \mathrm{L}$ TLC and equal number of cases in $8000-11000 \times 10^{9} / \mathrm{L}$ TLC i.e. 1 case each.

Overall incidence of our study in both the groups showed that patients infected with SSI $14(14 \%)$ cases in group I and $10(10 \%)$ in group II irrespective of their use of implants.

\section{DISCUSSION}

Postoperative wound infections have been shown to significantly increase morbidity, extend patients hospital stay, drastically increase the cost of medical system and causes severe physical limitations that diminish the quality of life. Decreasing the incidence of SSI is a matter of utmost interest to both patient and surgeon.

The use of prophylactic antibiotics is one of most important factor in decreasing infection and there is wide variability in duration of their use. Available literature recommends use of prophylactic antibiotics for 24 hours only. Administration of prophylactic antibiotics for longer than 24 hours has not been demonstrated to be effective and may actually lead to superinfection with drug resistant organisms. ${ }^{17}$

In our study, SSI among long term group was $14 \%$ and short term group was $10 \%$ which was statistically insignificant. Similar results have been quoted by Heydemann et al, Gultilo et al retrospectively compared outcomes for 1341 joint arthroplasties who had received prophylaxis for 3 days with 450 patients undergone similar procedure and received antibiotics prophylaxis for one day. ${ }^{8,18}$ Infection developed in $8(0.6 \%)$ of 1341 patients in first group compared with $3(0.67 \%)$ of 450 patients in second group.

Mean infection rate in one study was found out to be $12 \%$ which is higher in comparison to previously done studies (Table 3).
The lower incidence of infection in above studies may be attributed to better operative environment and hygiene practiced in operating room and better postoperative care.

Out of 200 patients, $137(68.5 \%)$ were males and 63 $(31.5 \%)$ were females. $14(10.21)$ out of 137 males developed SSI compared to $10(15.87 \%)$ out of 63 females developed SSI. Shrestha et al found out infection rate among males was nearly twice that of females. ${ }^{19}$

Table 3: Comparison of mean infection rates.

\begin{tabular}{|c|c|}
\hline Authors & Mean infection rate $(\%)$ \\
\hline Pavel et al ${ }^{16}$ & 2.85 \\
\hline Nadeem et al $^{20}$ & 11 \\
\hline Shrestha et al ${ }^{19}$ & 5.3 \\
\hline Ribeiro et $\mathbf{a l}^{21}$ & 17.24 \\
\hline Present study & 12 \\
\hline
\end{tabular}

Out of 200 patients, $54(27 \%)$ patients were more than 50 years age group and $146(73 \%)$ were below 50 years. Out of 54 patients above 50 years, 8 developed (14.81\%) developed infection, whereas $16(10.95 \%)$ out of 146 patients below 50 years age developed SSI. Shams Nadeem et al found out infection rate to be $>25 \%$ among patients more than 50 years. ${ }^{20}$ Increased infection rates among elderly may be attributed to low healing rates, malabsorption and low immunity.

Smoking was associated with higher incidence of SSI. 59 patients $(29.5 \%)$ were smokers and 141 (70.75\%) were non-smokers. Out of 59 patients who were smokers, 11 (18.64\%) developed SSI and $13(9.2 \%)$ out of 141 nonsmokers developed SSI. Nadeem et al, showed $25 \%$ infection rates among smokers in their study. ${ }^{20}$ Smoking has detrimental effect on tissue oxygenation, impairing reparative process of wound healing and neutrophil defence against surgical pathogens.

Average BMI in long duration group was 22.90 \pm 1.47 $\mathrm{kg} / \mathrm{m}^{2}$ and short duration group was $22.95 \pm 1.97 \mathrm{~kg} / \mathrm{m}^{2}$. Out of 200, $22(11 \%)$ patients had BMI >25 and 178 (89\%) had BMI <25.6 (27.27\%) out of 22 patients with BMI > 25 developed SSI compared to 18 (10.11\%) out of 178 with BMI $<25$. Nadeem et al, in their study found out BMI more than $40 \mathrm{~kg} / \mathrm{m}^{2}$ to be associated with higher rate of surgical site infection. ${ }^{20}$

Anaemia itself is not an established risk factor for SSI. However a higher incidence of SSI was noted in low preoperative $\mathrm{Hb}$ group. Mean $\mathrm{Hb}$ in long duration group without implant was $11.45 \pm 1.71 \mathrm{~g} / \mathrm{dl}$ and with implant was $11.43 \pm 2.71 \mathrm{~g} / \mathrm{dl}$ whereas mean $\mathrm{Hb}$ in short duration group without implant $11.37 \pm 1.67 \mathrm{~g} / \mathrm{dl}$ and with implant was $11.35 \pm 1.83 \mathrm{~g} / \mathrm{dl} .57(28.5 \%)$ patients had $\mathrm{Hb}<10 \mathrm{~g} / \mathrm{dl}$ of which $14(24.56 \%)$ developed SSI compared to 10 $(6.99 \%)$ out of $143(71.5 \%)$ patients with $\mathrm{Hb}>10 \mathrm{~g} / \mathrm{dl}$. It may be due to poor oxygen and nutritional delivery to tissues. Out of total 200 patients, $30(15 \%)$ had TLC 
more than reference range i.e. $11000 \times 10^{9} / 1.7(23.33 \%)$ out of these 30 developed SSI. Incidence of SSI among $170(85 \%)$ patients with TLC $<11000 \times 10^{9} / 1$ was 17 $(10 \%)$. Average duration of surgery in Long term antibiotics group was for implant procedure. $65.02 \pm 27.41$ minutes and non-implant procedure 53.66 \pm 23.97 minutes and that of short term antibiotics with implants $59.47 \pm 20.27$ minutes without implants $53.74 \pm 22.40$ minutes. 11 surgeries lasted more than 2 hours of which 2 $(18.18 \%)$ developed SSI whereas out of 189 surgeries lasting less than 2 hours. $22(11.64 \%)$ developed SSI. Shrestha et al, Ribeiro et al found increased rates of infection in surgeries lasting longer than 2 hours. ${ }^{19,21}$

\section{CONCLUSION}

In our study, there was no statistical difference between rate of infection among those who received two days intra-venous antibiotics and those who received antibiotics for five days. Thus, it was concluded that in clean orthopaedic elective surgeries short term antibiotics regimen is as effective as long term antibiotics regimen. Continuing antibiotics for more than two days is associated with drug related complications like allergic reactions and gastrointestinal upset, adverse interactions in other drugs, development of resistant organisms and it adds to overall cost of treatment.

\section{Funding: No funding sources}

Conflict of interest: None declared

Ethical approval: The study was approved by the institutional ethics committee

\section{REFERENCES}

1. Moynihan BGA. The ritual of surgical operation. $\mathrm{Br}$ J Surg.1920;8:27-35.

2. Horan TC, Andrus M, Dudeck MA. CDC/NHSN Surveillance definition of health care associated infection and criteria for specific types of infections in acute setting. Am J Infect Control. 2008;36:309-32.

3. Mangram AJ, Horan TC, Pearson ML, Silver LC, Jarvis WR. Guidelines for prevention of surgical site infection. Am J Infect Control. 1999;27:97-132.

4. Page CP, Bohnen JM, Fletcher JR, McManus AT, Solomkin JS, Wittmann DH. Antimicrobial prophylaxis for surgical wounds. Guidelines for clinical care. Arch Surg.1993;128:79-88.

5. Bratzler DW, Houck PM. An advisory statement from the National Surgical Infection Prevention Project. Clin Infect Dis. 2004;38:1706-15.

6. Marculescu CE, Osmon DR. Antibiotic prophylaxis in orthopedic prosthetic surgery. Infect Dis Clin North Am. 2005;19:931-46.

7. Meehan J, Jamali AA, Nguyen H. Psychosocial aspects of disabling musculoskeletal pain. J Bone J Surg Am 2009;91:2180-90.
8. Chambers HF. The emerging epidemiology of Staphylococcus aureus. Emerg Infect Dis. 2001;7: 178-82.

9. Williams D and Gustilo R. The use of preventive antibiotics in orthopaedic surgery. Clin OrthopRelat Res. 1984;190:83-8.

10. Ritter MA, Campbell E, Keating EM, Faris PM. Comparison of intraoperative versus 24 hour antibiotic prophylaxis in total joint replacement. A controlled prospective study. Orthop Rev. 1989; 18:694-6.

11. Mauerhan DR, Nelson CL, Smith DL. Prophylaxis against infection in total joint arthroplasty. One day of cefuroxime compared with three days of cefazolin, J Bone J Surg. 1994;76:39-45.

12. Bedouch P, Labar`ere J, Chirpaz E. Compliance with guidelines on antibiotic prophylaxis in total hip replacement surgery: results of a retrospective study of 416 patients in a teaching hospital. Infect Control Hosp Epidemiol. 2004;25:302-7.

13. Khorrami M, Tabatabaei S, Ahmadarabi M. The Efficacy of Short-Term vs. Long-term antibiotic therapy in preventing deep infection after orthopedic procedures (A prospective observational study). Jundishapur J Microbiol. 2012;5:427-9.

14. Forse RA, Karam B, Maclean D, Christou NV. Antibiotic prophylaxis for surgery in morbidly obese patients. Surgery. 1989;106:750-7.

15. Namias N, Harvill S, Ball S. Cost and morbidity associated with antibiotic prophylaxis in the ICU. J Am Coll Surg. 1999;188:225-8.

16. Pavel A, Smith RL, Ballard A, Larsen IJ. Prophylactic antibiotics in clean orthopaedic surgery. J Bone Joint Surg Am. 1974;56(4):777-782.

17. Trouillet JL, Chastre J, Vuagnat A, Joly-Guillou ML, Combaux D, Dombret MC, et al. Ventilator assosciated pneumonia caused by potentially drug resistant bacteria. Am J Respir Crit Care Med. 1998;157:531-9.

18. Heydemann JS, Nelson CL. Short-term preventive antibiotics. Clin Orthop Relat Res. 1986;205:184-7.

19. Shrestha BP, Niraula S, Nepal P, Khanal G, Karn N, Chaudhary $\mathrm{P}$, et al. Preoperative prophylactic antibiotics in orthopaedic surgery. Health Rennaissance. 2013;11:62-7.

20. Masood A, Alam SN, Khan O, Manzar S. Post operative wound infection:A surgeon's dilemma. Pakistan J surg. 2007:23(1):41-7.

21. Ribeiro CJ, Santos CB, Bellusse GC, Rezende VF, Galvao CM. Occurrence and risk factors for surgical site infection in orthopaedic sugery. Acta Paul Enferm. 2013;26(4):353-9.

Cite this article as: Chandrakar S, Mittal A, Jain J, Bansal H, Ahlawat P, Sangwan SS, et al. Efficacy of short term versus long term antibiotic therapy in preventing deep wound infections in elective orthopaedic surgeries. Int J Res Orthop 2020;6:1156-60. 